\title{
Optimisation of Multipurpose Reservoir Operation by coupling SWAT and Genetic Algorithm for Optimal Operating Policy (Case Study: Ganga River basin)
}

\author{
Jatin Anand ${ }^{1 *}$, A. K. Gosain ${ }^{2}$, and R. Khosa ${ }^{3}$ \\ ${ }^{1}$ Research Scholar, Department of Civil Engineering, Indian Institute of Technology Delhi, \\ New Delhi-110016, India. Email: anand.jatin8@gmail.com, jatinanandiit@gmail.com. \\ ${ }^{2}$ Professor, Department of Civil Engineering, Indian Institute of Technology Delhi, New \\ Delhi-110016, India. Email: gosain@ civil.iitd.ac.in. \\ ${ }^{3}$ Professor, Department of Civil Engineering, Indian Institute of Technology Delhi, New \\ Delhi-110016, India. Email: rakesh.khosa@gmail.com.
}

*Corresponding author: Jatin Anand; Email: anand.jatin8@gmail.com. 


\begin{abstract}
Reservoirs are recognized as one of the most efficient infrastructure components in integrated water resources management and development. At present, with the ongoing advancement of social economy and requirement of water, the water resources shortage problem has worsened, and the operation of reservoirs, in terms of consumption of flood water, has become significantly important. Reservoirs perform both regulation of flood and integrated water resources management, in which the flood limited water level is considered as the most important parameter for trade-off between regulation of flood and conservation. To achieve optimal operating policies for reservoirs, large numbers of simulation and optimization models have been developed in the course of recent decades, which vary notably in their applications and working. Since each model has their own limitations, the determination of fitting model for derivation of reservoir operating policies is challenging and most often there is always a scope for further improvement as the selection of model depends on availability of data. Subsequently, assessment and evaluation associated with the operation of reservoir stays conventional. In the present study, the Soil and Water Assessment Tool (SWAT) models and a Genetic Algorithm model has been developed and applied to two reservoirs in Ganga River basin, India to derive the optimal operational policies. The objective function is set to minimize the annual sum of squared deviation form desired irrigation release and desired storage volume. The decision variables are release for irrigation and other demands (industrial and municipal demands), from the reservoir. As a result, a simulation-based optimization model was recommended for optimal reservoir operation, such as allocation of water, flood regulation, hydropower generation, irrigation demands and navigation and e-flows using a definite combination of decision variables. Since the rule curves are derived through random search it is found that the releases are same as that of demand requirements. Hence based on simulated result, in the present case study it is concluded that GA-derived policies are promising and competitive and can be effectively used operation of the reservoir.
\end{abstract}

Keywords: Reservoir operation; SWAT; Genetic Algorithm; Urbanization; Ganga River. 


\section{Introduction}

The water concerns in the existing and foreseeable future will continue to be increasingly onerous and would turn out to be more and more intertwined with several evolving sectors, such as agriculture, energy, and manufacturing [1-3]. The impacts of changes in global climate has intensified furthermore to these challenges; thus, problems pertaining to water shortage demand more attention and additional actions [4-6]. There is increasing apprehensions regarding the requisite to formulate the balance between water demands and corresponding rivalling sectors, especially in river basins in which the majority of the water is allotted or exhausted. As a consequence of increase in population and various socio-economic advancement in the recent decades within the Ganga River Basin, the demand as well as claim for the available water has swollen, and assessing the demand and supply of available water turns out to be essentially urgent [7-9]. Most tropical and sub-tropical areas such as India, which is categorized by considerable annual and seasonal variations in precipitation. Such variability steps up the need for the development of infrastructure and the demand for the management of available water resources in an economic and sustainable way. The system analysis approach has been recognized as one of the most significant enhancements in the field of management of water resources, and has vast prospective in stipulating applicable provision for effective and efficient management in the emerging circumstance [10-12]. In the downstream area of the Ganga River, increase in population and intense agricultural and industrial development have all induced a tremendous increment in the demand of water demand. The demand for water from the regions outside of this basin is also escalating. Therefore, finding techniques to accomplish a safe, sustainable, and secure supply of water in this region has catch the attention of both government and society $[13,14]$.

In recent decades, considerable study has been conducted exercising optimization of reservoir to ascertain the optimal and efficient operating policies [15-18], and the stated area has become 
a major topic in examining the sustainability of existing water resources $[16,19,20]$. To curb the problem of inadequate supply of water during lean season, focus has been given on improving management of existing water resources, especially in optimization of operations and policies of reservoir $[18,21,22]$. Reservoirs has the ability to boost the dependability of water supply in fostering livelihoods, increasing agricultural yield, and reducing the susceptibility of farmers to droughts. A reservoir could suffice different objectives through water impounding and streamflow regulatory. Regular reservoir operational objectives comprise of control of flood, hydropower generation, agricultural, industrial and domestic water supplies, navigation, recreation, fisheries, and so on [10,22,23]. Moreover, the ecological and environmental issues that can result from operation of reservoir and diversion of water have also appealed to stake holders and decision makers [24-26]. Usually, most of the reservoirs in the world are accomplished by predefined operating policies [17,20,27,28]. Operating policies of reservoirs have been aimed for regulating release of water by keeping in mind the interests of the reservoir stakeholders and decision makers, volume of water impounded, inflows, demands of water, release capacity, and downstream constraints [29-31]. Loucks and van Beek, (2017) mentioned two types of operating policies in their study; one distinguishes the target water storage for a specific time, which is typically a distribution rule based on single target storage curve, whereas the other categorizes the reservoirs storage zones exercising multiple rule curves, which are correlated with specific distribution policies. In addition to, an exemplary operating policy should not only enhance the performance of the corresponding reservoir (e.g., minimize deficit in water supply, and maximize monetary benefits) but should also be able to accomplish preservation of hoarded water inside the reservoir [17,33-35]. However, more often than not there is the circumstance that a predefined policy may not able to accomplish the objectives of an ideal policy. Thus, refinement of the operational policy of the reservoirs is essential [27,36], and simulation of reservoirs along with 
the optimization algorithms can be an efficient and effective methodology for fine-tuning the rule curves [16,35]. Reservoir operation is a large scale multi-objective optimization problem including hydrology, agriculture, hydropower, reliability, and environment flows [37-39]. The development of operation of reservoir is a complicated problem, which includes multiple decision variables, several conflicting and contradictory objectives together with significant uncertainty and risk [16,28,36]. Designing and attaining operating rules for multi-reservoir systems is a challenging job and has been extensively generated during the scientific history of studies associated with the management of water resources [30,31,40]. Conventionally, operation of reservoir is accomplished based on heuristic measures, embracing rule curves and subjective decisions by the decision makers for release of reservoir conferring to the existing level of the reservoir, prevailing water demands, current hydrological conditions, and the period of the year. The expression rule curve or guide curve are predominantly utilized to represent operating policies that outline ideal or target storage levels and render a tool for release policies to be recognised as a function of stored water [41,42]. This offers typical operation policies, which does not permit optimized operations in response to alterations in the prevailing conditions. The problem becomes even more complex and intricate when the constraints or goals associated to quality of water are taken into consideration $[28,43]$. In the last decade, an array of approaches has been formulated based not only on conventional stochastic and probabilistic investigations, but also on the data and estimation of critical hydrologic events and advanced computational efficiency keeping in mind the end goal to build the efficiency and efficacy of the reservoir $[44,45]$. The operation of the reservoir is a nonconvex, nonlinear problem, however few of the academicians have employed a linear method to incorporate the methodology of linear programming for recommending their solution $[23,46]$. Reliability is the major concern among the researchers and necessitates that a complete 
stochastic approach is applied to decipher the problems of reservoir operation and, yet, only some of the researchers have undertaken to addressed this issue $[17,47]$.

A numerous amount of computer-based analytical techniques, from computation to optimization, are propounded for articulating, analysing, investigating, evaluating and explaining problems pertaining to water resources planning and management $[11,13,32]$. In the initial years, the majority of the optimization methods for the analysis of water resources systems incorporated dynamic programming (DP), linear programming (LP), and several nonlinear programming techniques. Several studies associated with water resources have previously applied these techniques complemented by auxiliary methods for a diverse range of problems $[32,48,49]$. Rapid advancements have transpired in these subjects, aided by highspeed computers, which have attributed to its development. During last decades, evolutionary optimization methods, viz. genetic algorithms, have become popular in the application of global optimization in the field of planning and management of reservoirs $[16,18,20,22,23,27,35,36,50]$. While, almost all the prevalent algorithms are accomplished in undertaking complicated and complex planning and management problems, evolutionary algorithms methods have been able to attract a vast amount of consideration vis-à-vis their capability in optimizing complex systems $[31,34,44]$. Advancement in high speed computing techniques have led to a vast number of researches, which employed EAs to different disciplines of water resources planning, operational and management problems [13,23], involving calibration of surface and ground-water [51,52], treatment of water [53] and operation policy of reservoirs [16,30,31]. Moreover, Abraham and Jain, (2005) indicated that there are numerous advantages in employing EAs since they demand comparatively less understanding regarding the prevailing questions being answered, are little susceptible to the Pareto front's continuity or their shape, are robust, could be easily implemented. The competence of EAs on anonymous objective functions involving several numerical and 
scientific characteristics, viz. non-differentiable, discontinuous, non-convex, and multimodal $[23,31,46]$, have been accounted in numerous researches. Evolutionary algorithms (EAs) have been comprehensively employed to a number of extents of water resources over the last decade, such as urban drainage and sewage schemes [55], water distribution systems [39,56], hydrologic and fluvial models [1], water supply and sewage treatment systems [13,44,55].

GAs, initially ascribed by Holland, (1975) and further developed by Goldberg, (1989), has been one of those developments, which has offered a potent tool for optimization. GAs, analogous to natural selection based on the renowned Darwinian theory, take into account the native genetic operators and the continued existence of the fittest in an effort to obtain the optimal solution in a considered set of solution $[10,17,32,56]$. They have become a handful tool for answering complicated problems of optimization in several different disciplines. Following the introduction of GA and its comprehensive utilisation in the different disciplines of water resources planning and management problems. Over the years, GAs have gained attention in the field of global optimization application to address storage reservoir optimization operation, planning and management [18,30,31,41,43,47,59]. Chang et al., (2005) employed a GA-based methodology to explore the optimal operational policy for the releases of water from reservoir, and then utilised these results in a developed ANFIS model. Oliveira and Loucks, (1997) applied GA to assess operating policies for multi-reservoir systems, indicating that GA could be utilised to determine the efficient and successful operational rules. Wardlaw and Sharif, (1999) also applied GAs to answer the reservoir operation problems optimally. Yuan et al., (2008) applied an advanced differential EA for optimal scheduling of hydro generation on a daily basis. Numerous researches have used EAs to manage the reservoir management problems realistically, particularly scheduling of release from the reservoir and the planning for hydropower generation $[10,16,20,23,31,33,62-64]$. Today, especially for 
reservoirs operation problems, EAs are acknowledged as suitable tools to support decisionmaking due to their multiple advantages.

The reality of an ever increasing urban population coupled with socioeconomic development in the last few decades over the Ganga River Basin, has substantially increased the demand for water, and the boundless need of the water management practices necessitates the study evaluating the water supply security $[65,66]$. Moreover, anthropogenic activities for example river operations and extensive regulations have tremendously significantly altered the water budget of the basin. In addition, the ecological and environmental problems associated with the operation of reservoir and water diversion have also attracted public concern $[6,67]$. In the downstream area of the Ganga River, ever increasing growth in the population and intense agricultural and industrial advancement have all developed into a considerable surge in the demand of water. Therefore, finding modes of water supply to attain a safe, economical, sustainable, and secure supply in this area, have enticed government, stakeholders, policy makers, decision makers, and society.

As explained before the water demand of this basin is also increasing. Therefore, finding methods to attain a secure, safe, and sustainable water supply in this area has appealed attraction from both people and administration. However, the simulation of credible flows for Ganga River Basin is the first step before optimizing the operation of reservoir as it is essential not only to manage the available water resources of the basin, but also to have a better knowledge of impact of possible future changes on availability of water [9]. Hydrological models are necessary for studying hydrologic processes and their responses to both endogenous and human factors, but due to complexity in the exemplification of complex natural conditions and processes, models must be calibrated prior to its application to attain a realistic match [6870]. Especially, water yields, inflows, irrigation water demand and overall water balance of a 
watershed can be simulated through the hydrologic simulations by the Soil and Water Assessment tool (SWAT) [71,72].

The objectives of our study are to (1) compute a variety of water demands (e.g., computation of irrigation water demand) in the Ganga River Basin, and then (2) figure out a number of optimal strategies for three distinctive reservoirs under different priorities to ensure the river's environmental health, while minimizing the water supply deficit and maximizing the hydropower generation as well.

\section{Study Area}

A multi-objective optimization model has been introduced to facilitate the operation of the reservoir in this study, for which two reservoirs namely Rihand dam and Tehri Dam, in the Ganga River Basin, India has been chosen to test for the new model.

\subsection{The Ganga River Basin}

Ganga river basin (GRB), which serves an area of about $1.08 \mathrm{Mkm}^{2}$ and covers a stretch of $1200 \mathrm{~km}$, finally meets the Bay of Bengal in the east. The Ganga River basin is situated in the northern part of the Indian sub-continent, encompassed within the latitudes of $22^{\circ} 30^{\prime}$ and $31^{\circ} 30^{\prime}$ North and the longitude of $73^{\circ} 30^{\prime}$ and $89^{\circ} 00^{\prime}$ East (Figure 1). The basin area of 0.86 $\mathrm{Mkm}^{2}$ in India, which is almost 26 percent of overall geographic area of the India, is distributed among eleven states (Bihar, Chhattisgarh, Himachal Pradesh, Haryana, Jharkhand, Madhya Pradesh, Punjab, Rajasthan, Uttar Pradesh, Uttarakhand, West Bengal, and the Union Territory of Delhi). The average annual rainfall in the GRB varies from $350 \mathrm{~mm}$ at the western end to $2000 \mathrm{~mm}$ near the delta at the eastern part. The amount of rainfall received by the basin not only changes throughout the region, it is also limited to only few months of the year mainly during monsoon months of June through October thus causing low flow conditions in the Ganga as well as its tributaries during the dry periods of November through May. Therefore, because of both intra and inter annual variability in precipitation and thus of surface runoff, the 
realistic distribution and allotment of water from the river through reservoirs is necessary for preserving, sustaining, exploiting, and managing water resources in this area.

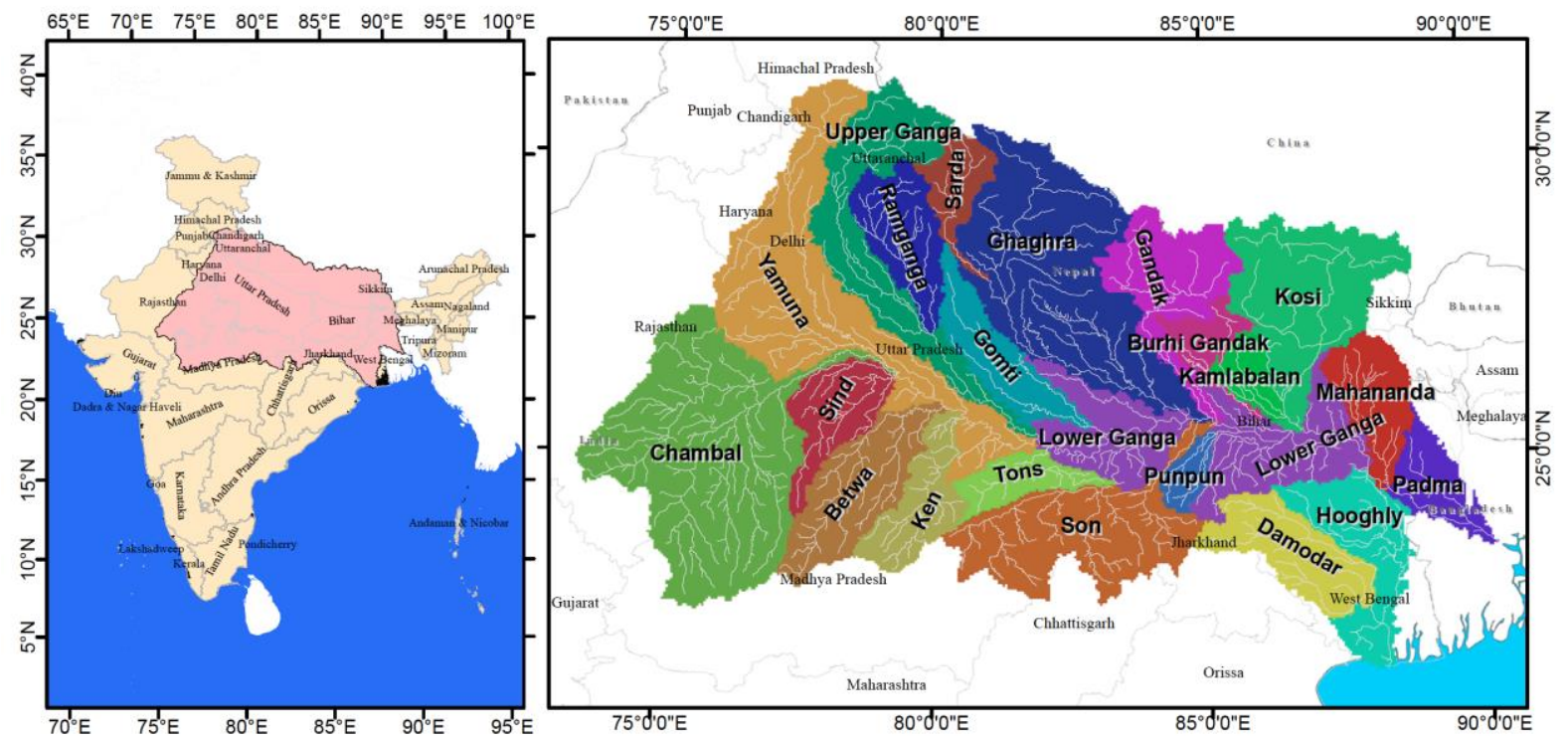

Figure 1. Location of the Ganga River Basin in India

\subsection{The Reservoirs}

Rihand dam is one of the Asia's largest man-made reservoirs developed. Reservoir's total area is roughly $457 \mathrm{~km}^{2}$. Total area of submergence is approximately 46,600 ha. The reservoir is a multiyear and multipurpose reservoir and came in to operate in 1962. Thus, the reservoir is of utmost importance to the people of the area. The released water courses towards north across the industrial regions and meets the Son river near Chopan. The water of reservoir is primarily utilised for
a) Drinking,
b) Irrigation,
c) Generation of hydroelectricity, and
d) Industrial purposes

The Tehri dam is situated near Tehri town in Uttarakhand in the Kumaon-Garhwal Himalaya, and is the Highest dam in India with a height of $260.5 \mathrm{~m}$. The dam creates a reservoir of 4.0 
cubic kilometres with a surface area of $52 \mathrm{~km}^{2}$. The water of reservoir is primarily utilised for drinking, irrigation, generation of hydropower, and industrial purposes.

\section{Data and methods}

The water quantity optimal operation model for reservoirs based on SWAT includes two segments. The first segment is the distributed hydrologic model (SWAT) coupling the operation of dams and floodgates. This part is the important and is effective in estimating hydrologic deviation at the basin scale and specify the essential boundary conditions for reservoir operation. The duration of study is from January 1960 to December 2014. The data employed involve the observed hydro-meteorology data over the study area, the reservoirs water levels, amount of the hydropower generation, and streamflow at different stations. The second segment is the optimal operation model for reservoirs, which would be employed to achieve two objectives, viz. maximizing available water resources and hydropower potential. The framework in Figure 2 illustrates the schematic diagram of the methodology adopted in this study, to achieve the objectives. 
Determine monthly Irrigation water need (Brouwer and Heibloem, (1986))

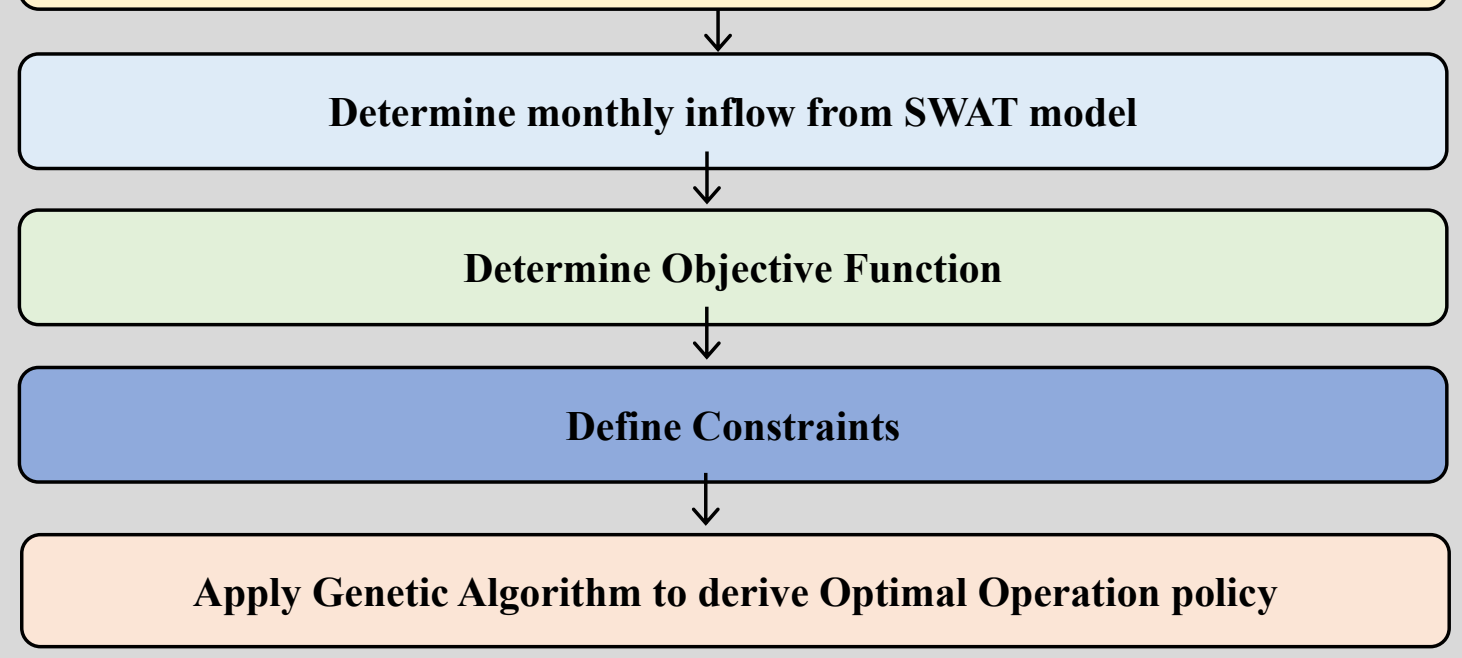

Figure 2. Schematic diagram of the methodology adopted in the study.

For optimizing the reservoirs operation, the total water demand is requisite. The aggregate water demand consists of the basic demands (e.g., for satisfying ecological and environmental needs, maintaining navigation, etc.), domestic and industrial water demands, and irrigation water demands. For the irrigation water demand, a traditional method for estimating crop water demand is employed.

\subsection{SWAT model}

The SWAT model is a physically based semi-distributed continuous time model developed by the United States Department of Agriculture (USDA) to explore the impact of climate land management practices on water, sediment and agricultural chemical yields in large un-gauged basins. SWAT can operate on a large basin and can simulate several processes such as flows in rivers, sediment transport and so on, on a daily/sub-daily time step [72,73]. SWAT simulates various hydrologic processes, including surface runoff generation, using either SCS curve number method or the Green and Ampt infiltration equation. For the quantification of 
evapotranspiration, SWAT model offers several approaches such as, Priestley-Taylor, Hargreaves, or Penman-Monteith methods. Groundwater flow, lateral flow and percolation are assessed through mass balance of the underlying system.

SWAT has been setup for the whole Ganga river basin [9]. The basin was discretized into 1045 sub- basins and 20628 Hydrological Response Units (HRUs) using Shuttle Radar Topographic Mission (SRTM) Digital Elevation Model (DEM) data (Jarvis et al., 2006), land cover data from National Remote Sensing Centre (NRSC), and soil attributes dataset from Food and Agriculture Organization (FAO) [9].

\subsection{Reservoir inflow}

The monthly inflow in the reservoir for each month $\mathrm{t}, \mathrm{I}$, is obtained from the calibrated and validated SWAT model [9]. The simulated surface runoff for the three reservoirs sub-basin for the 54- year period (1960-2013) has been derived from the SWAT model [9]. It should be noted that the SWAT simulation has been conducted at a daily time step, which has been aggregated to monthly data for use in this study.

Table 1. Historical Inflow for the Reservoirs

\begin{tabular}{ccc}
\hline & Rihand Dam & Tehri Dam \\
\hline January & 166.545144 & 113.3120556 \\
\hline February & 169.428168 & 64.7416728 \\
\hline March & 228.9121344 & 114.3283968 \\
\hline April & 215.5194 & 240.136056 \\
\hline May & 275.420988 & 457.9473636 \\
\hline June & 429.321384 & 822.317076 \\
\hline July & 1378.922904 & 1637.19432 \\
\hline August & 1847.47104 & 2137.63104 \\
\hline September & 1356.2208 & 1829.8332 \\
\hline October & 495.535248 & 1048.83912 \\
\hline November & 333.79452 & 527.2992 \\
\hline
\end{tabular}




\begin{tabular}{ccc}
\hline December & 248.459544 & 258.7446 \\
\hline Annual & 7145.551274 & 9252.324101 \\
\hline
\end{tabular}

\subsection{Irrigation water demand}

The water collected in the Rihand dam irrigates about 2.5 lakh hectares of the agricultural land. The power house has the installed capacity of $300 \mathrm{mw}$.

Irrigation water demand is usually estimated based on the method suggested by Brouwer and Heibloem, (1986). Irrigation water demand depends on crop water demand, which is defined as "the depth of water needed to meet the water loss through evapotranspiration (ETcrop) of a disease-free crop, growing in large fields under non-restricting soil conditions including soil water and fertility and achieving full production potential under the given growing environment" [74]. Consequently, to estimate the irrigation water demand for the target agricultural land, the following parameters were calculated: reference crop evapotranspiration, crop evapotranspiration, net irrigation, and actual irrigation water demand with consideration being given to both irrigation method and application efficiency [75].

\subsubsection{Reference crop evapotranspiration}

With the available weather data of temperature, humidity, wind speed and sunshine duration or radiation, a method was suggested by Brouwer and Heibloem, (1986) to compute the reference crop evapotranspiration, $\mathrm{ET}_{0}(\mathrm{~mm} / \mathrm{mon})$, as shown below:

$\mathrm{ET}_{0}=\mathrm{p}\left(0.46 \mathrm{~T}_{\text {mean }}+8\right)$

where, $\mathrm{p}=$ Mean Daily Percentage of Annual Daytime, $\mathrm{T}_{\operatorname{mean}}=\left(\mathrm{T}_{\max }+\mathrm{T}_{\min }\right) / 2$.

\subsubsection{Crop evapotranspiration}

After the estimation of reference crop evapotranspiration (ET0), the equation for computing crop evapotranspiration (ETcrop) is given below: 
$\mathrm{ET}_{\text {crop }}=\mathrm{K}_{\mathrm{c}} \cdot \mathrm{ET}_{0}$

where, $\mathrm{Kc}$ is the crop coefficient, which is associated with the characteristics of the crop and the stages of its growth.

\subsubsection{Net irrigation water demand}

As the difference between evapotranspiration of crop and effective rainfall is adopted to compute the required amount of irrigation water, it is imperative to assess the effective rainfall first. Furthermore, the effective rainfall indicates the quantity of the rainwater that gets infiltrated into the soil and subsequently gets evapotranspirated by the crops into the air (Doorenbos and Pruitt, 1977). Moreover, not all the rainfall which falls is effective as some portion of the rainfall might be lost because of surface runoff, canopy intervention, or evaporation (Doorenbos and Pruitt, 1977). However, these hydrological processes could be simulated by using physically based hydrological models (e.g., SWAT) [9]. In the present study, surface runoff, lateral flow, and seepage simulated by the SWAT model has been adopted, and the effective rainfall could be estimated from the equation below:

$R_{e f f}=P R E C-Q-L A T Q-S E E P$

where Reff is the effective rainfall, and PREC is precipitation reaching the soil surface, Q is surface runoff, LATQ is subsurface lateral flow (coming out of the root zone and meeting into the river), and SEEP is seepage from the bottom of the soil profile.

The net irrigation water demand, $\mathrm{Ir}_{\mathrm{net}}$, can be computed by the following equation:

$\mathrm{Ir}_{\text {net }}=$ Crop Water Requirement - Effective Rainfall $=\mathrm{ET}_{\text {crop }}-\mathrm{R}_{\mathrm{eff}}$

\subsubsection{Irrigation Water Demand}

Irrigation water demand has been computed based on the crop water requirement, effective rainfall and the efficiency of the irrigation. In this study, irrigation efficiency has been taken as 0.4 . 


\subsubsection{Estimation of Other Water Demands}

Apart from the irrigation demands, the water of the reservoirs is used to meet domestic viz. drinking and industrial demands, navigation, and the maintenance of minimum water in the downstream of the reservoir to sustain ecology, environmental and aquatic habitat. For the present study, other demands such as domestic and industrial demands have been contemplated as the constant requirements. The target release for the reservoirs is deliberated to be equal to the irrigation demand, while the storage is considered to be equal to the sum of the dead storage and the other necessary demands for the next three months. That is to say, that this would ensure that the three months of other necessary demands is achieved by the reservoir.

\subsection{Multi-objective optimization model}

Multi-objective optimization problems for the reservoirs involve the simultaneous optimization of several non-commensurable and often conflicting objectives. Often the reservoirs have two primary uses, generation of hydropower and supply sufficient quantity of water to meet irrigation demand. As can be seen that these objectives are generally conflicting in nature with each other, increase in the level of hydropower generation demands a higher water head, which means lesser amount of water releasing to meet irrigation demand. Likewise, the policy makers and decision makers should consider the probable trade-off between maximizing hydroelectric power generation and meeting irrigation and navigation requirements before reaching out for the most optimal policy.

\subsection{Genetic Algorithm Model Formulation}

Genetic Algorithms (GAs), proposed by John Holland (Holland, 1975; Goldberg, 1987), are a subset of evolutionary algorithms (EAs) that mimic processes observed in natural evolution to optimize an objective function (Haupt and Haupt 1998). GAs, analogous to Darwinian natural 
selection, is a search procedure based on the mechanism of natural selection, evolution, and natural genetics, through generations to search in an attempt to find the best solution.

GA lets a set comprised of different entities (solution points) and steered random searches to evolve under stated selection policies to the point, which maximizes/minimizes the considered objective function (Goldberg 1989). Like other EAs, GAs does not need derivatives information to assess optimal solutions. GAs can be employed to accomplish a local as well as global search in a large search space (Srivastava et al. 2002). The fundamentals necessary for GAs to commence are the parameter representation needed to be optimized, the genetic operator, and the objective function. The decision variables of an optimization problem are programmed to a single artificial chromosome in the whole GA population, which can be outlined as one of the many likely solutions of the given optimisation problem. The fitness of a chromosome as a candidate solution to a problem is based on a measure of the objective function represented by it, to evaluate the probability of survival. The GA search starts with an initial randomly generated population of chromosomes, and combined through genetic operators namely selection, crossover, and mutation, to improve the evaluation of solutions by generating fitter chromosomes through iterations. The selection process is essentially to select chromosomes in the gene pool with a higher fitness values for survival or generating offspring in the population of the subsequent generation. Following the evaluation of fitness function, selection was performed by roulette wheel selection (Goldberg, 1989), analogous to the crucial mechanism of the "Survival of the fittest", to form the next generation, with each slice of a roulette wheel proportioned to fitness values. Therefore, the strings having higher fitness value will have a greater probability of being copied to the next generation. The information of the two likely solutions of the given optimisation problem is reciprocated through crossover between two random positions. Single-point crossover or multi-point crossover is elected on a random basis. Mutation is a key method, which allows introduction of new genetic material to 
a population. Mutation allows the modification of a string to a stipulated extent, that could be both negative or positive. Following the mutation, the fitness of the function is again computed to obtain the optimal solution of the given decision variables.

\subsection{Genetic Algorithm Model Development}

In the present study, the primary objectives of the optimization of reservoir model are to minimize the water supply deficit, and to maximize hydropower generation. The aforementioned objectives of the optimisation problem are mutually conflicting/competitive as hydropower generation demands higher head in the reservoir to maximize power production and subsequently generate more energy. However, supply of water to meet irrigation and other demands necessitates release of water to meet these demands.

\subsubsection{Rihand Dam and Tehri Dam}

In this study, the objective function of the GA model (the fitness function) for the Rihand dam and Tehri Dam, is minimizing the squared deviation of monthly irrigation demand deficit and the deviation in the target storage and maximization of hydropower generation. The following equation represents the mathematical equation of the optimization model: To minimize water supply deficit;

Minimize $S Q D V=\sum_{t=1}^{12}\left[\left(R_{t}-D_{t}\right)^{2}-\left(S_{t}-S_{T}\right)^{2}\right]$

where, $D_{t}=$ irrigation demand during the month ' $t$ ', $R_{t}=$ irrigation release during the month ' $\mathrm{t}$ ', $\mathrm{S}_{\mathrm{T}}=$ target storage in $\mathrm{Mm} 3$, and $\mathrm{S}_{\mathrm{t}}=$ initial storage during the month ' $\mathrm{t}$ '

To maximize the energy production, following equation represents the mathematical equation of the optimization model:

Maximize $E=\sum_{t=1}^{12} p\left(R_{t} H_{t}\right)$ 
where $\mathrm{E}$ is the total energy produced in $\mathrm{M} \mathrm{kwh}$ (million $\mathrm{kwh}$ ); $\mathrm{p}$ is power production coefficient; $\mathrm{R}_{\mathrm{t}}$ is the release to riverbed turbine in period $\mathrm{t}$ in $\mathrm{Mm}^{3}$; and $\mathrm{H}_{\mathrm{t}}$ are the net head available to turbine in meters during period $t$.

The optimization of the reservoir optimization problem is subjected to the following constraints:

\subsubsection{Mass balance constraint}

The correlation between the month to month storage is driven by the continuity equation. The continuity equation is stated as,

$\mathrm{S}_{\mathrm{t}+1}=\mathrm{S}_{\mathrm{t}}+\mathrm{Q}_{\mathrm{t}}-\mathrm{R}_{\mathrm{t}}-\mathrm{E}_{\mathrm{t}}-\mathrm{O}_{\mathrm{t}} \quad \mathrm{t}=1,2,3, \ldots, 12$

where, $S_{t+1}=$ final storage in the month ' $t$ ', $Q_{t}=$ inflow during the month ' $t$ ', $E_{t}=$ Evaporation loss in the reservoir during time period ' $\mathrm{t}$ ' and $\mathrm{O}_{\mathrm{t}}=$ Surplus from the reservoir during month ' $\mathrm{t}$ '.

\subsubsection{2. $\quad$ Release constraint}

The water released for the irrigation during any month should be less than or equal to the irrigation demand in that month and this constraint is represented by the following equation,

$\mathrm{R}_{\mathrm{t}} \leq \mathrm{D}_{\mathrm{t}}, \quad \mathrm{t}=1,2,3, \ldots, 12$

\subsubsection{3. $\quad$ Storage Limits}

The storage of the reservoir during any month must not be surplus than the defined capacity of the reservoir, and must not be lower than the defined dead storage. Mathematically, this constraint is given as:

$\mathrm{S}_{\min } \leq \mathrm{S}_{\mathrm{t}} \leq \mathrm{S}_{\max }$

for all $\mathrm{t}=1,2,3, \ldots, 12$

\subsubsection{Over flow constraint}

This constraint manages the condition, once the final storage surpasses the maximum defined limit of the reservoir. Mathematically this constraint is given by: 
$\mathrm{O}_{\mathrm{t}}=\mathrm{S}_{\mathrm{t}+1}-\mathrm{S}_{\max }$

and, Ot $\geq 0$ $\mathrm{t}=1,2,3, \ldots, 12$

$\mathrm{t}=1,2,3, \ldots, 12$

\subsubsection{5. $\quad$ Maximum Power Production Limits}

$\mathrm{p} \mathrm{R}_{\mathrm{t}} \mathrm{H}_{\mathrm{t}} \leq \mathrm{E} \quad 0 \quad \mathrm{t}=1,2,3, \ldots, 12$

where, $\mathrm{E}$ is the maximum amounts of power in $\mathrm{M} \mathrm{kwh} \mathrm{(million} \mathrm{kwh}$ ) that can be produced; $\mathrm{p}$ is power production coefficient; $\mathrm{R}_{\mathrm{t}}$ is the release to riverbed turbine in period $\mathrm{t}$ in $\mathrm{Mm}^{3}$; and $\mathrm{H}_{\mathrm{t}}$ are the net head available to turbine in meters during period t.

\section{Results and discussion}

The reservoir optimization / simulation model characterised by Eqn. (5) - Eqn. (12) is adopted in the Rihand Dam, and Tehri Dam to obtain the operative policies for optimizing multiple objectives of water supply and hydropower generation. In the present study of GA model, monthly inflow into the reservoir system and, the monthly irrigation demands are the two critical input variables. The primary goal is to estimate the quantity of water released to meet the total demand. That is to say the objective function for the optimisation of reservoir is based on the reservoir releases at every time step, therefore, water releases must be the decision variable upon which the GA is centred around. Also, the only unknown variable in the optimisation of reservoir operation model is the target storage ( $\mathrm{St})$, and it is computed by applying the GA for every month to minimize the water supply deficit and to maximize the hydropower generation.

For this study, three scenarios coupled with three priority conditions has been devised to simulate the optimization model. For the first scenario, the objective function is to minimize the deficit of water supply only, designated as the supply priority scenario. Whereas for the second scenario, designated as the power priority the objective function is to maximize the 
hydropower generation only. While the third scenario aims at maximizing the advantages of both supply priority scenario and the power priority scenario simultaneously. Therefore, while the first two scenarios are to operate the reservoir with a specific and solitary objective, the third scenario involves two conflicting/competitive objectives with equal priorities. However, basic water demand must be met to warrant the environmental health of the river, irrespective of the three scenarios.

Employing the aforementioned three optimisation scenarios and the GA optimization technique, the target reservoir storages are accomplished for the different operating policies. Figure 3 and Figure 4 pictures the associated target reservoir storage. From Figure 3 and Figure 4, it has been noted that to meet the demand in the first scenario (supply priority), it requires larger water release from the Rihand and Tehri dam and consequently lower water level, resulting in the smallest attained final storages. On the other hand, the second scenario demands impounding of water in the reservoir at a higher level to create more head and thus generating more energy. That is to say, the reservoir managers and associated authority are inclined to hold the water in the reservoir, resulting in the highest attained target storages. However, for the equal priority, the optimized target storages are in between the scenarios first and the second. Although the three reservoir operating rule curves derived serve different purposes, in spite of that, the constraint ensuring that the attainment of basic surface runoff demands enumerated in the reservoir optimization model, can ensure the minimum streamflow in the river and thus, warrant the environmental health of the river. The other possible and optional operational, storage and release policies would be able to support the reservoir authority and policy makers in formulating an efficient and sustainable guideline for several conflicting/competing priorities rendered and for diverse inflow scenarios. The multi-objective GA approach is thus very much useful, in producing a well-defined solution set for the 
conflicting objectives and eventually helps for better operation requiring short computational time.

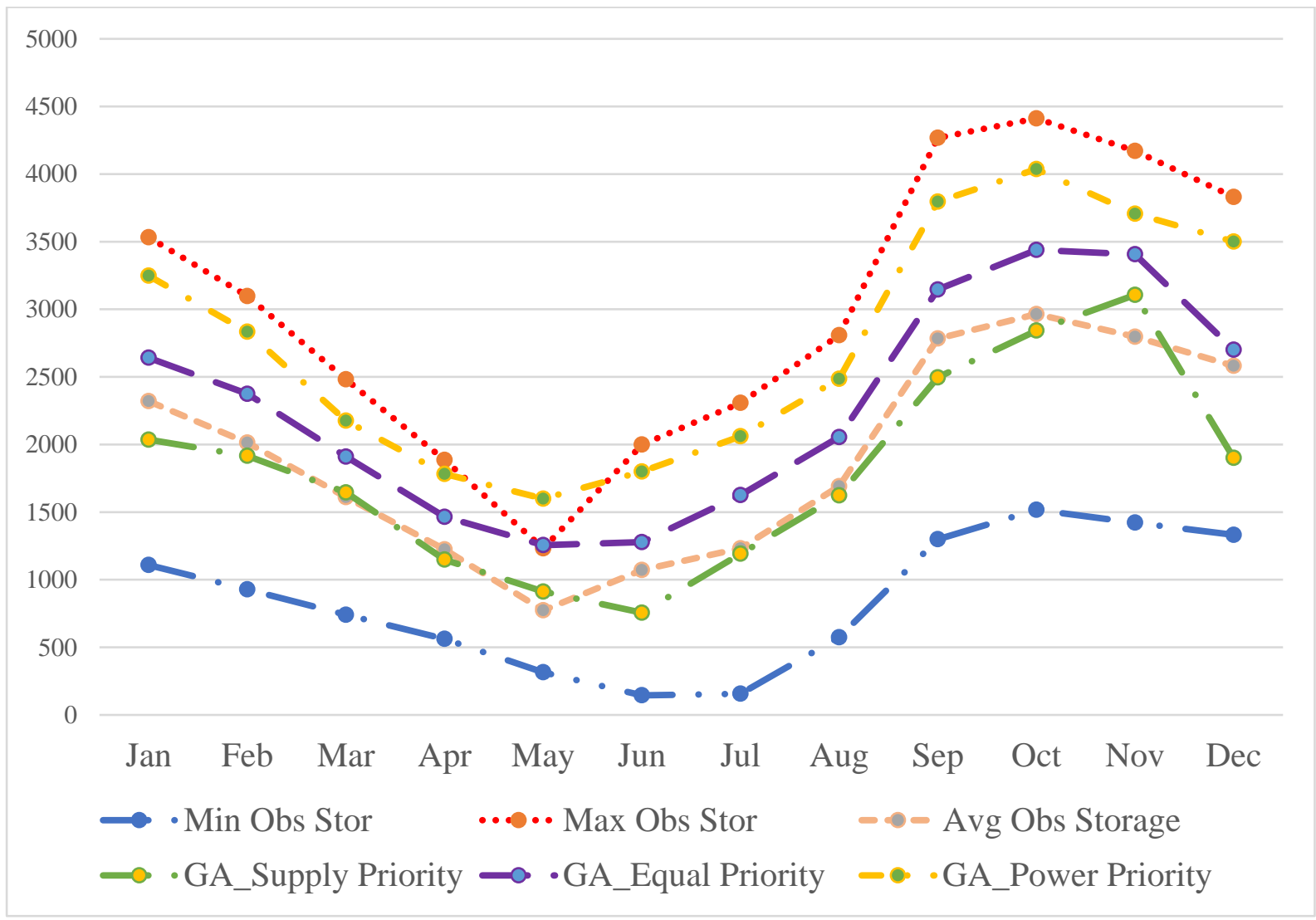

Figure 3. Target Storage for Rihand Dam for three scenarios 


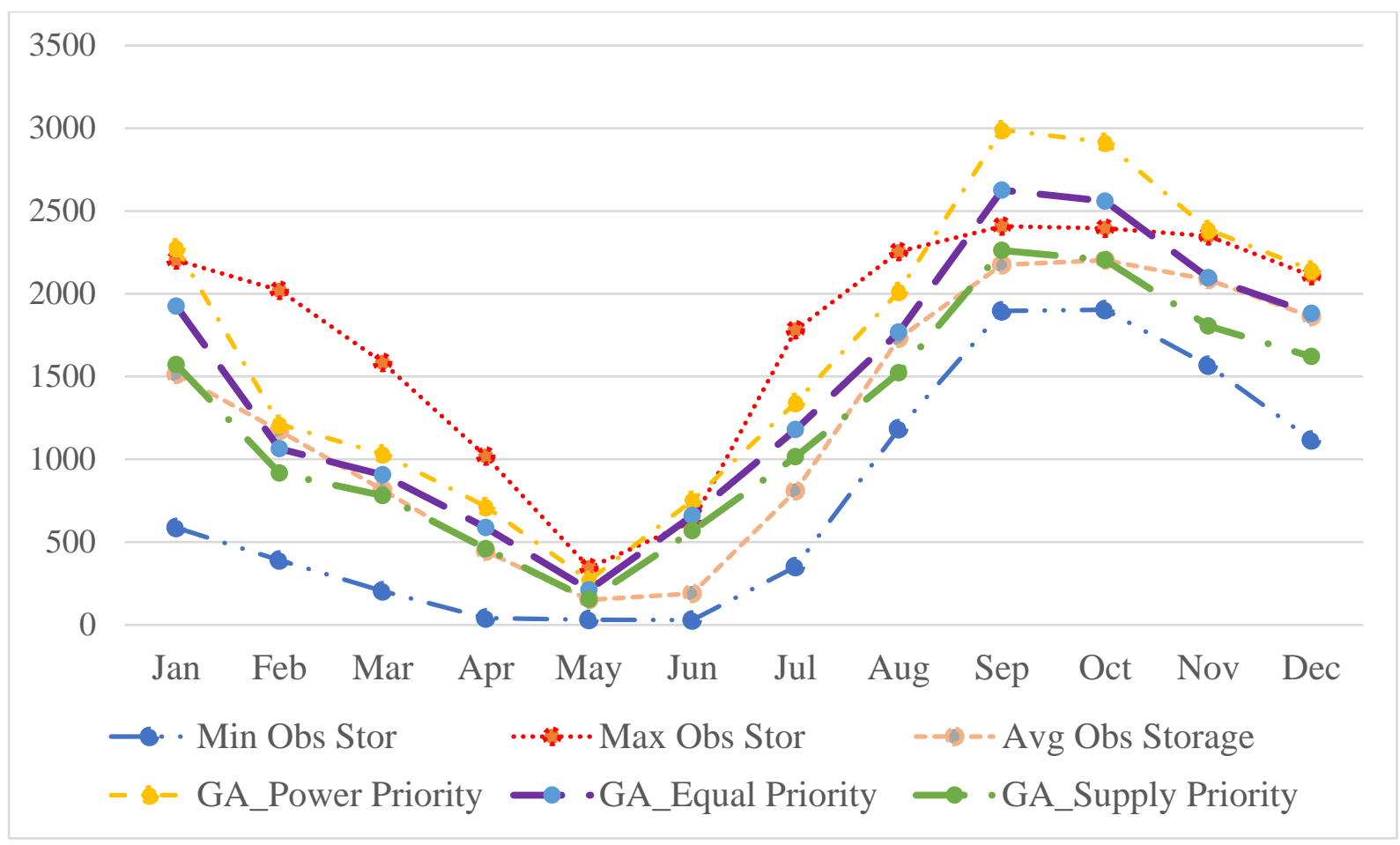

Figure 4. Target Storage for Tehri Dam for three scenarios

Nowadays, with the rapid increase in the population and consequently increase in the demands, the ecological health of the river and the shortage of water supply have progressively developed into a prominent problem and thus, have been able to attract the concerns of both government and the public. Predominantly the revamp of the operating policies of the reservoirs could influence the way in which the reservoirs are being operated to meet the demands. However, added unforeseen and serious complications such as mitigating flood might stop the reservoir operators from attaining the desired target or final storages. Yet, the endeavour to accomplish the optimal operating policies should help in warranting the sustainability of river ecosystem and diminish water supply deficit, while undertaking hydropower generation and serving added demands. Hence, the optimal final storage obtained in this research may provide decision makers and reservoir operators with informative and valuable information needed for efficient operation of the Rihand and Tehri reservoir. 


\section{Summary and Conclusion}

Conventional optimization model offers merely single optimal solution in a particular simulation, and applies a preference vector which necessitates extremely careful alterations to attain optimal solutions. Nevertheless, Multi-objective Genetic Algorithm could attain nondominated solutions to multi-objective problems in a single simulation employing the population-by-population methodology. Genetic algorithms propose a dominant optimization methodology and have popularly established itself in reservoir operation planning and management; however, rising numbers of variables demands large amount of computation, and ends into a very time-consuming evolution amid successive generations, therefore abruptly reducing the likelihood of converging into an optimum solution. In addition, the efficacy and effectiveness of the solution does not depend on a function outlined by the operator and decision makers, subsequently these objective functions could be employed precisely without demanding any transformations.

Evolutionary computation methods exhibit huge prospective in optimizing complicated problems. In this study, a Multi-Objective Genetic Algorithm approach has been successfully employed for the problem of the optimization of the operation of multi-objective reservoir. The foremost benefit of the Multi-Objective Genetic Algorithm methodology is its ability in able to discover several Pareto optimal solutions in a particular simulation, that is both efficient and effective too at the same time and supports the operators and decision makers to make fitting assessments and decisions in diverse situations. This research suggests a constrained genetic algorithm for the planning and management of multi-purpose reservoir that includes meeting of human requirement and generation of hydropower requirements. A multi-objective model is articulated incorporating hydropower and irrigation as the two conflicting/competing objectives and the multi-objective reservoir optimization model, exercising a combination of the SWAT simulation model and Genetic Optimisation Algorithm, is applied to derive efficient 
reservoir operation policies for Rihand reservoir system and Tehri Reservoir system, in India, in order to minimize annual sum of squared deviation of irrigation release and target storage and to maximize the reservoir hydropower generation. The three operating policies of reservoirs (i.e., final storage) conforming to the three priority scenarios (water supply only, power generation only, and equal priority) has been developed. Under the new operation policy, optimised by GA, the trade-off concerning meeting the irrigation and other demands and generation of hydropower has been resolved. An optimal solution has been determined, which is proficient enough in sufficing the numerous demands and generation of hydropower, as compared to the contemporary procedures. The balanced optimum solution could uphold a higher level of water in the reservoir, and at the same time meet the several downstream demands. Additionally, the optimised policy may amplify the generation of hydropower during the flood season as well as increase the likelihood of accessibility of water for the subsequent dry season. In this study, optimal solutions for the regulations reservoir have been accomplished. The assessment of the results implies that the operation of the reservoir for hydropower generation and water supply can be enhanced considerably. The optimization model for the two reservoirs is robust and adaptable in serving multi-objectives under several priorities. Thus, this research has been successfully able to exhibit the efficiency and effectiveness of Multi-Objective Genetic Algorithm for varying multi-objective reservoir operation strategies. It has been exhibited that the technique has been efficient in optimising the rule curves managing the operation of the reservoirs in a multi-objective framework.

\section{Acknowledgements}

The authors would like to thank Indian Institute of Technology Delhi (India) for providing support for conducting this study. We appreciate the data support from the Central Water 
Commission (http://www.cwc.nic.in/) and also from the Indian Meteorological Department (IMD). We also thank the editor and two anonymous reviewers for their invaluable comments.

\section{Conflict of Interest}

The authors declare that they have no conflict of interest.

\section{References}

1. Brown, C. M.; Lund, J. R.; Cai, X.; Reed, P. M.; Zagona, E. A.; Ostfeld, A.; Hall, J.; Characklis, G. W.; Yu, W.; Brekke, L. The future of water resources systems analysis: Toward a scientific framework for sustainable water management. Water Resour. Res. 2015, 51, 6110-6124, doi:10.1002/2015WR017114.

2. Davies, E. G. R.; Simonovic, S. P. Global water resources modeling with an integrated model of the social-economic-environmental system. Adv. Water Resour. 2011, 34, 684-700, doi:10.1016/j.advwatres.2011.02.010.

3. Rockström, J.; Karlberg, L.; Wani, S. P.; Barron, J.; Hatibu, N.; Oweis, T.; Bruggeman, A.; Farahani, J.; Qiang, Z. Managing water in rainfed agriculture-The need for a paradigm shift. Agric. Water Manag. 2010, 97, 543-550, doi:10.1016/j.agwat.2009.09.009.

4. Franczyk, J.; Chang, H. The effects of climate change and urbanization on the runoff of the Rock Creek basin in the Portland metropolitan area, Oregon, USA. Hydrol. Process. 2009, 23, 805-815, doi:10.1002/hyp.7176.

5. IPCC Climate Change 2014. Impacts, Adaptation, and Vulnerability Part A: Global And Sectoral Aspects; 2014; Vol. 53;.

6. Zhang, A.; Zhang, C.; Fu, G.; Wang, B.; Bao, Z.; Zheng, H. Assessments of Impacts of Climate Change and Human Activities on Runoff with SWAT for the Huifa River Basin, 
Northeast China. Water Resour. Manag. 2012, 26, 2199-2217, doi:10.1007/s11269012-0010-8.

7. Mishra, A.; Singh, R.; Raghuwanshi, N. S.; Chatterjee, C.; Froebrich, J. Science of the Total Environment Spatial variability of climate change impacts on yield of rice and wheat in the Indian Ganga Basin. Sci. Total Environ. 2013, doi:10.1016/j.scitotenv.2013.05.080.

8. Narula, K. K.; Gosain, A. K. Modeling hydrology, groundwater recharge and non-point nitrate loadings in the Himalayan Upper Yamuna basin. Sci. Total Environ. 2013, 468469 Su, S102-16, doi:10.1016/j.scitotenv.2013.01.022.

9. Anand, J.; Gosain, A. K.; Khosa, R.; Srinivasan, R. Regional scale hydrologic modeling for prediction of water balance, analysis of trends in stream flow and variations in stream flow: The case study of the Ganga River basin. J. Hydrol. Reg. Stud. 2018, 16, 32-53, doi:10.1016/j.ejrh.2018.02.007.

10. Wang, K. W.; Chang, L. C.; Chang, F. J. Multi-tier interactive genetic algorithms for the optimization of long-term reservoir operation. Adv. Water Resour. 2011, 34, $1343-$ 1351, doi:10.1016/j.advwatres.2011.07.004.

11. Yeh, W. W.-G. Reservoir Management and Operations Models '. Water Resour. Res. 1985, 21, 1797-1818, doi:10.1029/WR021i012p01797.

12. Kadigi, R. M. J.; Mdoe, N. S. Y.; Ashimogo, G. C.; Morardet, S. Water for irrigation or hydropower generation?-Complex questions regarding water allocation in Tanzania. Agric. Water Manag. 2008, 95, 984-992, doi:10.1016/j.agwat.2008.03.008.

13. Nicklow, J.; Reed, P.; Savic, D.; Dessalegne, T.; Harrell, L.; Chan-Hilton, A.; Karamouz, M.; Minsker, B.; Ostfeld, A.; Singh, A.; Zechman, E. State of the Art for Genetic Algorithms and Beyond in Water Resources Planning and Management. J. Water Resour. Plan. Manag. 2010, 136, 412-432. 
14. Kim, T.; Heo, J.-H.; Jeong, C.-S. Multireservoir system optimization in the Han River basin using multi-objective genetic algorithms. Hydrol. Process. 2006, 20, 2057-2075, doi:10.1002/hyp.6047.

15. Bozorg-Haddad, O.; Janbaz, M.; Loáiciga, H. A. Application of the gravity search algorithm to multi-reservoir operation optimization. Adv. Water Resour. 2016, 98, 173185, doi:10.1016/j.advwatres.2016.11.001.

16. Wu, Y.; Chen, J. Estimating irrigation water demand using an improved method and optimizing reservoir operation for water supply and hydropower generation: A case study of the Xinfengjiang reservoir in southern China. Agric. Water Manag. 2013, 116, 110-121, doi:10.1016/j.agwat.2012.10.016.

17. Chang, L. C. Guiding rational reservoir flood operation using penalty-type genetic algorithm. J. Hydrol. 2008, 354, 65-74, doi:10.1016/j.jhydrol.2008.02.021.

18. Chang, F.-J.; Chen, L.; Chang, L.-C. Optimizing the reservoir operating rule curves by genetic algorithms. Hydrol. Process. 2005, 19, 2277-2289, doi:10.1002/hyp.5674.

19. Momtahen, S.; Dariane, A. B. Direct Search Approaches Using Genetic Algorithms for Optimization of Water Reservoir Operating Policies. 2007, 202-209.

20. Lerma, N.; Paredes-Arquiola, J.; Andreu, J.; Solera, A.; Sechi, G. M. Assessment of evolutionary algorithms for optimal operating rules design in real Water Resource Systems. Environ. Model. Softw. 2014, 69, doi:10.1016/j.envsoft.2014.09.024.

21. Jian-Xia, C.; Qiang, H.; Yi-min, W. Genetic Algorithms for Optimal Reservoir Dispatching. Water Resour. Manag. 2005, 19, 321-331, doi:10.1007/s11269-005-30185.

22. Chou, F. N. F.; Wu, C. W. Stage-wise optimizing operating rules for flood control in a multi-purpose reservoir. J. Hydrol. 2015, 521, 245-260, doi:10.1016/j.jhydrol.2014.11.073. 
23. Yang, T.; Gao, X.; Sellars, S. L.; Sorooshian, S. Improving the multi-objective evolutionary optimization algorithm for hydropower reservoir operations in the California Oroville-Thermalito complex. Environ. Model. Softw. 2015, 69, 262-279, doi:10.1016/j.envsoft.2014.11.016.

24. Chung, E.-S.; Lee, K. S. Prioritization of water management for sustainability using hydrologic simulation model and multicriteria decision making techniques. J. Environ. Manage. 2009, 90, 1502-1511, doi:10.1016/j.jenvman.2008.10.008.

25. Li, Y. P.; Huang, G. H.; Nie, S. L. Optimization of regional economic and environmental systems under fuzzy and random uncertainties. 2011, 92, doi:10.1016/j.jenvman.2011.03.022.

26. Matrosov, E. S.; Huskova, I.; Kasprzyk, J. R.; Harou, J. J.; Lambert, C.; Reed, P. M. Many-objective optimization and visual analytics reveal key trade-offs for London's water supply. J. Hydrol. 2015, 531, 1040-1053, doi:10.1016/j.jhydrol.2015.11.003.

27. Ngo, L. Le; Madsen, H.; Rosbjerg, D. Simulation and optimisation modelling approach for operation of the Hoa Binh reservoir, Vietnam. J. Hydrol. 2007, 336, 269-281, doi:10.1016/j.jhydrol.2007.01.003.

28. Zhang, Y.; Xia, J.; Chen, J.; Zhang, M. Water quantity and quality optimization modeling of dams operation based on SWAT in Wenyu River Catchment, China. Environ. Monit. Assess. 2011, 173, 409-430, doi:10.1007/s10661-010-1396-5.

29. Khan, N. M.; Tingsanchali, T. Optimization and simulation of reservoir operation with sediment evacuation: a case study of the Tarbela Dam, Pakistan. Hydrol. Process. 2008, 2274, 2267-2274, doi:10.1002/hyp.

30. Jothiprakash, V.; Shanthi, G. Single Reservoir Operating Policies Using Genetic Algorithm. Water Resour. Manag. 2006, 20, 917-929, doi:10.1007/s11269-005-9014$\mathrm{y}$. 
31. Reddy, M. J.; Kumar, D. N. Optimal reservoir operation using multi-objective evolutionary algorithm. Water Resour. Manag. 2006, 20, 861-878, doi:10.1007/s11269005-9011-1.

32. Loucks, D. P.; van Beek, E. Water Resource Systems Planning and Management; 2017; ISBN 978-3-319-44232-7.

33. Chang, L. C.; Chang, F. J.; Wang, K. W.; Dai, S. Y. Constrained genetic algorithms for optimizing multi-use reservoir operation. J. Hydrol. 2010, 390, 66-74, doi:10.1016/j.jhydrol.2010.06.031.

34. Chang, L. C.; Chang, F. J. Multi-objective evolutionary algorithm for operating parallel reservoir system. J. Hydrol. 2009, 377, 12-20, doi:10.1016/j.jhydrol.2009.07.061.

35. Wei, C. C.; Hsu, N. S. Optimal tree-based release rules for real-time flood control operations on a multipurpose multireservoir system. J. Hydrol. 2009, 365, 213-224, doi:10.1016/j.jhydrol.2008.11.038.

36. Ndiritu, J.; Odiyo, J.; Makungo, R.; Mwaka, B.; Mthethwa, N.; Ntuli, C.; Andanje, A. Development of probabilistic operating rules for Hluhluwe Dam, South Africa. Phys. Chem. Earth 2017, 100, 343-352, doi:10.1016/j.pce.2016.10.017.

37. Wardlaw, R.; Sharif, M. Evaluation of Genetic Algorithms for Optimal Reservoir System Operation. J. Water Resour. Plan. Manag. 1999, 125, 25-33, doi:10.1061/(ASCE)0733-9496(1999)125:1(25).

38. Wurbs, R. A. Reservoir-System Simulation and Optimization Models. J. Water Resour. Plan. Manag. 1993, 119, 455-472.

39. Bashiri-Atrabi, H.; Qaderi, K.; Rheinheimer, D. E.; Sharifi, E. Application of Harmony Search Algorithm to Reservoir Operation Optimization. Water Resour. Manag. 2015, 29, doi:10.1007/s11269-015-1143-3.

40. Lund, J. R.; Ferreira, I. Operating Rule Optimization for Missouri River Reservoir 
System. J. Water Resour. Plan. Manag. 1996, 122, 287-295, doi:10.1061/(ASCE)07339496(1996)122:4(287).

41. Kumphon, B. Genetic Algorithms for Multi-objective Optimization: Application to a Multi-reservoir System in the Chi River Basin, Thailand. Water Resour. Manag. 2013, 27, 4369-4378, doi:10.1007/s11269-013-0416-y.

42. Ahmad, A.; El-Shafie, A.; Razali, S. F. M.; Mohamad, Z. S. Reservoir Optimization in Water Resources: a Review. Water Resour. Manag. 2014, 28, 3391-3405, doi:10.1007/s11269-014-0700-5.

43. Kaini, P.; Artita, K.; Nicklow, J. Optimizing Structural Best Management Practices Using SWAT and Genetic Algorithm to Improve Water Quality Goals. Water Resour. Manag. 2012, 26, 1827-1845, doi:10.1007/s11269-012-9989-0.

44. Labadie, J. W. Optimal Operation of Multireservoir Systems: State-of-the-Art Review. J. Water Resour. Plan. Manag. 2004, 130, 93-111, doi:10.1061/(ASCE)07339496(2004)130:2(93).

45. Madani, K.; Lund, J. R. A Monte-Carlo game theoretic approach for Multi-Criteria Decision Making under uncertainty. Adv. Water Resour. 2011, 34, 607-616, doi:10.1016/j.advwatres.2011.02.009.

46. Chaves, P.; Chang, F.-J. Intelligent reservoir operation system based on evolving artificial neural networks. Adv. Water Resour. 2008, 31, 926-936, doi:10.1016/j.advwatres.2008.03.002.

47. Hınçal, O.; Altan-Sakarya, A. B.; Metin Ger, A.; Hin??al, O.; Altan-Sakarya, A. B.; Ger, A. M. Optimization of Multireservoir Systems by Genetic Algorithm. Water Resour. Manag. 2011, 25, 1465-1487, doi:10.1007/s11269-010-9755-0.

48. Cai, X.; McKinney, D. C.; Lasdon, L. S. A framework for sustainability analysis in water resources management and application to the Syr Darya Basin. Water Resour. Res. 2002, 
38, 21-1-21-14, doi:10.1029/2001WR000214.

49. Duckstein, L.; Opricovic, S. Multiobjective optimization in river basin development. Water Resour. Res. 1980, 16, 14, doi:10.1029/WR016i001p00014.

50. Cai, X.; McKinney, D. C.; Lasdon, L. S. Solving nonlinear water management models using a combined genetic algorithm and linear programming approach. Adv. Water Resour. 2001, 24, 667-676, doi:10.1016/S0309-1708(00)00069-5.

51. Qi, W.; Zhang, C.; Fu, G.; Zhou, H. Quantifying dynamic sensitivity of optimization algorithm parameters to improve hydrological model calibration. J. Hydrol. 2016, 533, 213-223, doi:10.1016/j.jhydrol.2015.11.052.

52. Huang, X.; Liao, W.; Lei, X.; Jia, Y.; Wang, Y.; Wang, X.; Jiang, Y.; Wang, H. Parameter optimization of distributed hydrological model with a modified dynamically dimensioned search algorithm. Environ. Model. Softw. 2014, 52, 98-110, doi:10.1016/j.envsoft.2013.09.028.

53. van Griensven, a.; Meixner, T. A global and efficient multi-objective auto-calibration and uncertainty estimation method for water quality catchment models. $J$. Hydroinformatics 2007, 9, 277, doi:10.2166/hydro.2007.104.

54. Abraham, A.; Jain, L. Evolutionary Multiobjective Optimization; 2005; ISBN 1852335831.

55. Guo, Y.; Walters, G.; Savic, D. Optimal design of storm sewer networks: Past, present and future. Integr. Assess. Decis. Support 2008, 1, 1-10.

56. Goldberg, D. E.; Kuo, C. H. Genetic Algorithms in Pipeline Optimization. J. Comput. Civ. Eng. 1987, 1, 128-141, doi:10.1061/(ASCE)0887-3801(1987)1:2(128).

57. Holland, J. H. Adaptation in Natural and Artificial Systems: An introductory Analysis with Applications to Biology, Control and Artificial Intelligence. MIT Press 1975, 183, doi:10.1137/1018105. 
58. Goldberg, D. E. Genetic Algorithms in Search, Optimization \& Machine Learning; 1989;

59. Ahmed, J. A.; Sarma, A. K. Genetic algorithm for optimal operating policy of a multipurpose reservoir. Water Resour. Manag. 2005, 19, 145-161, doi:10.1007/s11269005-2704-7.

60. Oliveira, R.; Loucks, D. P. Operating rules for multireservoir systems. Water Resour. Res. 1997, 33, 839-852, doi:10.1029/96WR03745.

61. Yuan, X.; Zhang, Y.; Wang, L.; Yuan, Y. An enhanced differential evolution algorithm for daily optimal hydro generation scheduling. Comput. Math. with Appl. 2008, 55, 2458-2468, doi:10.1016/j.camwa.2007.08.040.

62. Hakimi-Asiabar, M.; Ghodsypour, S. H.; Kerachian, R. Deriving operating policies for multi-objective reservoir systems: Application of Self-Learning Genetic Algorithm. Appl. Soft Comput. J. 2010, 10, 1151-1163, doi:10.1016/j.asoc.2009.08.016.

63. Cheng, C.-T.; Wang, W.-C.; Xu, D.-M.; Chau, K. W. Optimizing Hydropower Reservoir Operation Using Hybrid Genetic Algorithm and Chaos. Water Resour. Manag. 2008, 22, 895-909, doi:10.1007/s11269-007-9200-1.

64. Reddy, M. J.; Kumar, D. N. Multiobjective Differential Evolution with Application to Reservoir System Optimization. J. Comput. Civ. Eng. 2007, 21, 136-146, doi:10.1061/(ASCE)0887-3801(2007)21:2(136).

65. Chawla, I.; Mujumdar, P. P. Isolating the impacts of land use and climate change on streamflow. Hydrol. Earth Syst. Sci. 2015, 19, 3633-3651, doi:10.5194/hess-19-36332015.

66. Barik, B.; Ghosh, S.; Sahana, A. S.; Pathak, A.; Sekhar, M. Water Food Energy Nexus: Changing Scenarios in India during recent Decades. Hydrol. Earth Syst. Sci. Discuss. 2016, 1-30, doi:10.5194/hess-2016-647. 
67. Chung, S. W.; Ko, I. H.; Kim, Y. K. Effect of reservoir flushing on downstream river water quality. J. Environ. Manage. 2008, 86, 139-147, doi:10.1016/j.jenvman.2006.11.031.

68. Fukunaga, D. C.; Cecílio, R. A.; Zanetti, S. S.; Oliveira, L. T.; Caiado, M. A. C. Application of the SWAT hydrologic model to a tropical watershed at Brazil. CATENA 2015, 125, 206-213, doi:10.1016/j.catena.2014.10.032.

69. Futter, M. N.; Whitehead, P. G.; Sarkar, S.; Rodda, H.; Crossman, J. Rainfall runoff modelling of the Upper Ganga and Brahmaputra basins using PERSiST. Environ. Sci. Process. Impacts 2015, 17, 1070-1081, doi:10.1039/C4EM00613E.

70. Sahoo, G. B.; Ray, C.; De Carlo, E. H. Calibration and validation of a physically distributed hydrological model, MIKE SHE, to predict streamflow at high frequency in a flashy mountainous Hawaii stream. J. Hydrol. 2006, 327, 94-109, doi:10.1016/j.jhydrol.2005.11.012.

71. Arnold, J. G.; Srinivasan, R.; Muttiah, R. S.; Williams, J. R. Large area hydrologic modeling and assesment Part I: Model development. JAWRA J. Am. Water Resour. Assoc. 1998, 34, 73-89, doi:10.1111/j.1752-1688.1998.tb05961.x.

72. Neitsch, S. L.; Arnold, J. G.; Kiniry, J. R.; Srinivasan, R.; Williams, J. R. Soil and Water Assessment Tool User's Manual; 2002;

73. Arnold, J. G.; Kiniry, J. R.; Srinivasan, R.; Williams, J. R.; Haney, E. B.; Neitsch, S. L. Soil \& Water Assessment Tool: Input/output documentation. version 2012. Texas Water Resour. Institute, TR-439 2013, 650.

74. Doorenbos, J.; Pruitt, W. O. Guidelines for predicting crop water requirements. FAO Irrig. Drain. Pap. 1977, 24, 144.

75. Drastig, K.; Prochnow, A.; Libra, J.; Koch, H.; Rolinski, S. Irrigation water demand of selected agricultural crops in Germany between 1902 and 2010. Sci. Total Environ. 
2016, 569-570, 1299-1314, doi:10.1016/j.scitotenv.2016.06.206. 